\title{
Empirical Study of Happiness Experience of Sewage Treatment Facilities in Beijing Villages and Towns
}

\author{
Zhang Ruozhou ${ }^{\mathrm{a}}$, Chen Huazhang ${ }^{\mathrm{b}}$, Li Moyang ${ }^{\mathrm{c}}$ \\ School of Economics and Management, Beijing Jiaotong University, Beijing, China

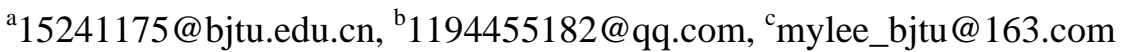

Keywords: sewage treatment facilities, Beijing villages and towns, happiness, interview and investigation, empirical analysis

\begin{abstract}
The function of infrastructure is reflected not only in economic growth and other hard indexes, but also in subjective assessment such as happiness of user experience and so on. Based on happiness index, this paper constructs the analysis model to measure the degree of happiness experience of sewage treatment facilities in villages and towns, and empirically analyzes the experience value of the facilities taking Beijing surrounding villages and towns as a sample. It is considered that the experience value of happiness includes two subjects, villagers and users, and different subjects have different sources of happiness; Different treatment models, village committees' cognition and service, daily management of facilities and objective condition of villages and towns can significantly impact the happiness of sewage treatment facilities in villages and towns, different operating models impact the happiness in a different manner, and PPP model can remarkably improve the happiness of sewage treatment facilities compared with BOT model.
\end{abstract}

\section{Research Background and Significance}

In recent years, the construction of villages and towns has received attention from various parties. Sewage treatment facilities are an important component in the infrastructure of villages and towns, and whether it is constructed and operated well directly relates to the production and life quality of residents in villages and towns. For Beijing with rapid development of constructing sewage treatment facilities, although there are multiple sewage treatment stations whose operating condition is great overall, how to assess the social value of these sewage treatment facilities in villages and towns remains a significant issue.

Meanwhile, different from existing studies which simply express subjective value as the subjective feelings of beneficiaries, this paper holds that the experiencers of infrastructure subjective value include not only direct beneficiaries, but also tourists, investigator and other users. Because other user groups are less impacted by life experience, historical factors, and emotional factors of towns and villages, and they are able to make a horizontal comparison among towns and villages, their assessments apparently can make up for the deficiency that villagers only can conduct longitudinal assessments.

\section{Literature Review}

Most generally accepted concept of happiness that the analysis of infrastructure subjective value is based on happiness index is "the emotional state human individuals evoke when they realize that their needs are satisfied and their ideals are achieved, and is a complex and multi-layered psychological state formed by the interaction between psychological factors such as needs (including motive, desire and interest), cognition and emotion and external inducement" (Li Yan and Zhao Jun, 2004). Since this concept appeared in the 1950s, it has transformed from the level of psychology and philosophy to that of empirical analysis like index construction, along with people's increasing attention on life quality and development of health psychology and positive psychology. Currently, the most frequently used measurement methods are the Life Satisfaction 
Index (LSI) proposed by Neugarten and the Satisfaction With Life Scale (SWLS) by Diener (1985).

According to current studies, measurement methods for the happiness of rural sewage treatment can be divided into two levels: First, results are classified into five categories by directly inquiring whether users are happy. When this method is applied, most studies choose second-hand data from Chinese General Social Survey and Chinese Family Panel Studies as data source. Using data in 2010 China's Interprovincial Green Development Index and Chinese General Social Survey (CGSS), Li Shunyi (2017) conducted an empirical analysis, finding that green development is conducive to promote happiness from state and urban and rural level, however, its influence on rural residents' happiness is not significant. Utilizing 2010 baseline data of Chinese Family Panel Studies, Wang Bing and Yang Bao (2018) investigated the influence of villages' expenditure scale and structure on peasants' happiness, and discovered that the expenditure scale of villages has remarkable influence on happiness. Villagers' happiness experience improves with the increased expenditure ratio of villages' public service and infrastructure; while the influence of administrative expenditure ratio of villages on villagers' happiness is not remarkable.

Second, by introducing second grade index of happiness experience, the measurement index of infrastructure subjective value is constructed. Such measurement method mostly adopts field research for data acquisition and empirical examination. Using micro investigation data, Guo Lei and Xiao Youzhi (2016) measured the influence of governmental regulation reform on residents' happiness, associated water affairs regulation reform with water price and popularizing rate, and divided residents' happiness index into three parts with different weights. They found that governmental water affairs regulation reform exerts positive influence on the improvement of residents’ happiness.

\section{Model Method and Index Design}

\subsection{Model method}

Starting from the perspective of demand, this paper describes the happiness differences caused by sewage treatment operating models of different villages and towns by taking the happiness index constructed as criterion. In this paper, the happiness subjects fall into two group types, villagers and external users represented by tourists and observers. The happiness index constructed by equal weight method is as follows:

$$
\text { index } X=\frac{\sum_{i=1}^{n} D_{i}}{\mathrm{n}}, X=1,2,3
$$

Where, $\mathrm{D}_{\mathrm{i}}$ is the component factors of happiness, $\mathrm{n}$ is the number of component factors, which can be divided into index1, index2 and index3. The component factors of index2 are villagers' cognition degree of sewage treatment facilities, influence of sewage treatment facilities on villagers, and differences before and after construction of sewage treatment facilities; the component factors of index3 include natural environment in villages and towns, water quality in villages and towns, and working conditions of sewage treatment, and index 1 is comprised of all the above indexes.

Assuming that all assessment variables and corresponding experience are positively correlated, that is, the larger the index is, the better the happiness experience of corresponding subjects for sewage treatment facilities will be.

For the influential factors of happiness, this paper holds that in addition to sewage treatment model, village committees' cognition and service, and daily management of sewage treatment facilities, some objective variables such as population and distance also exert influence on happiness. Therefore, stepwise regression is adopted in this paper to measure the influence of the above factors on user happiness, and the overall regression model is as follows:

$$
V=\beta_{0}+\beta_{1} \cdot \text { Model }_{i}+\beta_{2} \cdot C_{i}+\beta_{3} \cdot G_{i}+\beta_{4} \cdot K_{i}
$$

Where, $\mathrm{V}$ denotes the happiness index, Model is the dummy variable of different investment and operating models, different investment modes are set as $0,1,2, \ldots$, respectively; $C_{i}$ is the cognitive variable group of village committees, $G_{i}$ represents the daily management variable group of facilities, and $K_{i}$ is the objective condition variable group of villages and towns. In this model, the 
three happiness indexes, index1, index2 and index3 produced by Eq. (1) are substitute into equation as dependent variables, and regressed for several times by stepwise regression, and the size and significance of $\beta_{i}$ are used to characterize the influence of each factor on corresponding happiness index.

\subsection{Index design}

Nine villages and towns distributed in five districts, Changping, Shunyi, Fangshan, Mentougou and Yanqing are selected, which are Habatun Village, Chenzhuang Village, Hongnigou Village, Mazhuang Village and Zhaoling Village respectively. Field investigation is used to conduct a field survey in villages and towns, the authors communicate and understand situation with local villagers and relevant persons in charge of local village committees, and carry out questionnaire survey.

All questionnaires are composed of three parts, villagers' happiness assessment of sewage treatment facilities (9), tourists' happiness assessment of sewage treatment facilities (8), and village committees' attitudes towards sewage treatment facilities (8). According to data requirement of empirical analysis, the sewage treatment models in villages and towns are set as two-valued dummy variable, when the treatment model is BOT, the two-valued dummy variable is set as 0 ; when the treatment model is PPP, the variable is set as 1 , the rest variables use 5-point Likert scale to quantify the answers of the above module, and the value range is the integers between 1-5. The specific index design is shown in Table 1, and Table 2 demonstrates the descriptive statistics of relevant variable data in empirical analysis.

Table 1 Modeling explanation variable table

\begin{tabular}{|c|c|}
\hline Variable name & Variable explanation \\
\hline Sewage treatment model（Model） & $\begin{array}{l}\text { Dummy variable. } \\
\text { BOT is set as } 0 \text {, PPP } \\
\text { is set as } 1\end{array}$ \\
\hline \multicolumn{2}{|l|}{ Villagers' happiness assessment: } \\
\hline Villagers' happiness index (index2) & Dependent variable \\
\hline Villagers' cognition degree of sewage treatment facilities (recg) & Dependent variable \\
\hline Influence of sewage treatment facilities on villagers (influnc) & Dependent variable \\
\hline $\begin{array}{l}\text { Environmental difference before and after sewage treatment } \\
\text { facilities construction }\end{array}$ & Dependent variable \\
\hline \multicolumn{2}{|l|}{ Group members’ happiness assessment: } \\
\hline Group members’ happiness index (index 3) & Dependent variable \\
\hline Natural environment in villages and towns (nenv) & Dependent variable \\
\hline Water quality in villages and towns (wtrq) & Dependent variable \\
\hline Working condition of sewage treatment facilities (wrkc) & Dependent variable \\
\hline \multicolumn{2}{|l|}{ Village committees’ cognition and service } \\
\hline $\begin{array}{l}\text { Disclosure willingness to positional information of treatment } \\
\text { facilities (M1) }\end{array}$ & Control variable \\
\hline Disclosure willingness to construction information (M2) & Control variable \\
\hline Cognition degree of facilities’ management method (G1) & Control variable \\
\hline Cognition degree of facilities’ management system (G2) & Control variable \\
\hline \multicolumn{2}{|l|}{ Daily management: } \\
\hline Facilities’ maintenance frequency (W1) & Control variable \\
\hline Facilities’ daily supervision degree (W2) & Control variable \\
\hline \multicolumn{2}{|l|}{ Objective variable: } \\
\hline Average income per capita in villages and towns (averg) & $\begin{array}{l}\text { Control } \\
\text { Unit: yuan }\end{array}$ \\
\hline Distance to urban center from villages and towns & $\begin{array}{l}\text { Control } \\
\text { Unit: km }\end{array}$ \\
\hline
\end{tabular}

Notes: Each variable (except sewage treatment model variable and objective variable) is set as 1-5 
Table 2 Descriptive statistics of questionnaire survey data

\begin{tabular}{cccccc}
\hline Variable & Sample size & Average value & Standard deviation & Minimum value & Maximum value \\
\hline Model & 93 & 0.705 & 0.462 & 0 & 1 \\
recg & 93 & 2.061 & 1.746 & 1 & 5 \\
influnc & 93 & 4.167 & 1.224 & 1 & 5 \\
diff & 93 & 2.265 & 1.364 & 1 & 5 \\
nenv & 93 & 3.477 & 0.606 & 1 & 5 \\
wtrq & 93 & 3.318 & 1.100 & 1 & 5 \\
wrkc & 93 & 3.219 & 1.12 & 1 & 5 \\
M1 & 93 & 3.409 & 0.871 & 1 & 5 \\
M2 & 93 & 2.886 & 1.466 & 1 & 5 \\
W1 & 93 & 3.409 & 3.273 & 1 & 5 \\
W2 & 93 & 0.871 & 1.208 & 1 & 5 \\
G1 & 93 & 3.181 & 0.870 & 1 & 5 \\
G2 & 93 & 3.386 & 0.689 & 1 & 5 \\
G3 & 93 & 2.727 & 1.065 & 1 & 51.7 \\
Avrginc & 9 & 15701.838 & 1082.776 & 14095 & 28.4 \\
Distance & 9 & 42.7 & 8.743 & & \\
\hline
\end{tabular}

\section{Stepwise Regression}

Stepwise regression is used in this paper, to examine the correlation between happiness and each factor.

According to regression of overall happiness and each factor, the four characterization variables, treatment model, village committees' cognition and service, daily management and objective variable have relatively significant influence on overall happiness, which mostly maintain above $5 \%$ significance level. After adding other factors, the influence of treatment model on happiness still maintains above 1\% significance level, and the sewage treatment facilities which adopt PPP model bring remarkably higher happiness than that adopting BOT model; The objective condition of villages and towns also remains above $5 \%$ significance level for the promotion of happiness. In the aspect of numerical influence, the higher the per capita income level is, the farther the distance is to urban center, the higher the happiness experience of sewage treatment facilities will be. Although there are some fluctuations in the significance of overall happiness' influence of village committees' cognition and service and facilities' daily management on sewage treatment, generally speaking, with the improvement of village committees' cognitive level, service capacity, and responsible persons' daily management to treatment facilities, they will have a significantly positive influence on the overall happiness.

Table 3 Influence coefficient and significance of each variable on overall happiness

\begin{tabular}{|c|c|c|c|c|c|c|c|}
\hline \multirow{2}{*}{$\begin{array}{c}\text { Treatment model } \\
\text { Model }\end{array}$} & \multicolumn{4}{|c|}{$\begin{array}{c}\text { Village committees' cognition and } \\
\text { service }\end{array}$} & \multicolumn{2}{|c|}{ Daily management } & Objective variable \\
\hline & M1 & M2 & G1 & G2 & W1 & W2 & distance \\
\hline \multicolumn{8}{|l|}{$3.413^{* * *}$} \\
\hline & $0.161 *$ & $0.345^{* * *}$ & $0.304 * *$ & $0.294 *$ & & & \\
\hline & & & & & $0.797 * * *$ & $0.062 *$ & \\
\hline & & & & & & & $0.001^{* * *} \quad 0.037^{* * *}$ \\
\hline $1.797 * * *$ & 0.083 & -0.118 & -0.323 & $0.598 * * *$ & & & \\
\hline $1.590 * * *$ & & & & & $0.606 * * *$ & -0.048 & \\
\hline $0.712 * * *$ & & & & & & & $0.001^{* * *} \quad 0.019^{* * *}$ \\
\hline $0.769 * * *$ & & & & & 0.061 & $0.084^{*}$ & $0.001^{* * *} \quad 0.014$ \\
\hline \multirow{2}{*}{$1.293^{* * *}$} & $0.599 * * *$ & $0.267 * * *$ & $1.136^{* * *}$ & $1.249 * * *$ & 0.0899 & $-0.939 * * *$ & \\
\hline & $1.297 * * *$ & -0.031 & $1.864 * * *$ & $1.371^{* * *}$ & $0.575 * * *$ & $-1.498 * * *$ & \\
\hline $0.976 * * *$ & $0.132 * *$ & $0.173^{* * *}$ & $0.643^{* * *}$ & $0.619 * * *$ & $0.133^{* *}$ & $0.474 * * *$ & $0.000^{* * *} \quad 0.012^{* * *}$ \\
\hline
\end{tabular}

Notes: $*, * *$, and $* *$ represent examination passing of $10 \%, 5 \%$, and $1 \%$ significance level, respectively. Similarly hereinafter.

Then, stepwise regression is made to villagers' happiness and tourists' happiness respectively, to 
analyze the influence of each factor on the two concrete happiness.

Results of stepwise regression show that the influence of villagers' happiness, treatment model, daily maintenance of treatment facilities and objective condition of villages and towns remains basically at $1 \%$ significance level, and the influence direction and extent are basically consistent with overall significance. However, the significance level of influence of village committees' cognition and service on villagers' happiness is unstable, which is significant below $1 \%$, and also can be non-significant.

Table 4 Influence coefficient and significance of each variable on villagers' happiness

\begin{tabular}{|c|c|c|c|c|c|c|c|c|}
\hline \multirow{2}{*}{$\frac{\text { Treatment model }}{\text { Model }}$} & \multicolumn{4}{|c|}{$\begin{array}{c}\text { Village committees' cognition and } \\
\text { service }\end{array}$} & \multicolumn{2}{|c|}{ Maintenance management } & \multicolumn{2}{|c|}{ Objective variabl } \\
\hline & M1 & M2 & G1 & G2 & W1 & W2 & averg & distance \\
\hline & -0.055 & $0.288^{* * *}$ & $0.377^{* * *}$ & $0.302 *$ & & & & \\
\hline & & & & & $0.651^{* * *}$ & $0.168^{* *}$ & & \\
\hline & & & & & & & $0.001^{* * *}$ & $0.019 * *$ \\
\hline $1.288^{* * *}$ & -0.007 & $-0.043 * *$ & 0.136 & $0.521^{* *}$ & & & & \\
\hline $1.381 * * *$ & & & & & $0.486^{* * *}$ & $0.073^{* *}$ & & \\
\hline \multirow[t]{4}{*}{$0.704^{* * *}$} & & & & & & & $0.001 * * *$ & $0.003^{* *}$ \\
\hline & $-0.848 *$ & -0.043 & $1.657^{*}$ & $1.180^{* *}$ & $0.111^{*}$ & $1.121^{* * *}$ & & \\
\hline & 0.053 & $0.125^{*}$ & $0.174 * *$ & $-0.253^{*}$ & & & $0.001^{* * *}$ & $0.013^{* *}$ \\
\hline & & & & & $0.115^{* *}$ & $0.086^{* *}$ & $0.001 * * *$ & $0.022^{* *}$ \\
\hline $0.451^{* *}$ & 0.059 & 0.045 & 0.107 & -0.111 & & & $0.001 * * *$ & $0.007 *$ \\
\hline $0.0725 * * *$ & -0.114 & $-0.141 *$ & $0.822 *$ & 0.656 & $0.303^{* *}$ & $0.479 * *$ & $0.001 * *$ & 0.002 \\
\hline
\end{tabular}

Influence of tourists' happiness, treatment model, village committees' cognition and service, and objective condition of villages and towns continues to maintain at $1 \%$ significance level, and the influence direction is basically the same as overall significance. While the influence of daily management of sewage treatment facilities on tourists' happiness is not highly significant, maintaining basically below $5 \%$ level.

Table 5 Influence coefficient and significance of each variable on tourists’ happiness

\begin{tabular}{|c|c|c|c|c|c|c|c|c|}
\hline \multirow{2}{*}{$\begin{array}{c}\text { Treatment model } \\
\text { Model }\end{array}$} & \multicolumn{4}{|c|}{$\begin{array}{l}\text { Village committees' cognition and } \\
\text { service }\end{array}$} & \multicolumn{2}{|c|}{ Daily management } & \multicolumn{2}{|c|}{ Objective variable } \\
\hline & M1 & M2 & G1 & G2 & W1 & W2 & averg & distance \\
\hline \multicolumn{9}{|l|}{$3.629 * * *$} \\
\hline & $0.088^{*}$ & $0.401^{* * *}$ & $0.23 * *$ & $0.285 * * *$ & & & & \\
\hline & & & & & $0.943 * *$ & $-0.451^{*}$ & & \\
\hline & & & & & & & $0.001 * * *$ & $0.053 * * *$ \\
\hline $2.306^{* * *}$ & $0.173^{*}$ & $0.193^{* *}$ & $0.201^{* *}$ & $0.675^{* * *}$ & & & & \\
\hline $1.798 * * *$ & & & & & 0.728 & $1.698 * *$ & & \\
\hline \multirow[t]{2}{*}{$0.720^{* * *}$} & & & & & & & $0.001^{* * *}$ & $0.035 * * *$ \\
\hline & $1.745^{* * *}$ & $0.019 * *$ & $2.071^{* * *}$ & $1.561 * * *$ & $1.041 *$ & $-1.875^{* *}$ & & \\
\hline $1.671^{* * *}$ & $0.844 * * *$ & $0.323^{* * *}$ & $1.131^{* * *}$ & $1.404^{* * *}$ & $0.413^{*}$ & 1.154 & & \\
\hline $0.828 * * *$ & & & & & $0.147 *$ & -0.149 & $0.001^{* * *}$ & $0.027 * * *$ \\
\hline $1.227 * * *$ & $0.151 * * *$ & $0.207 * * *$ & $0.464 * * *$ & $0.583^{* * *}$ & $-0.038 * '$ & -0.469 & $0.0003 * * *$ & $0.024 * * *$ \\
\hline
\end{tabular}

Through empirical examination, it is found that treatment model, village committees' cognition and service, daily management of treatment facilities, and objective condition of villages and towns has a significant influence on happiness of sewage treatment facilities in villages and towns, which specifically reflects in the influence of treatment model, daily management of treatment facilities, and objective condition of towns and villages on villagers' happiness, and the influence of treatment model, village committees' cognition and service, and objective variable on tourists' happiness. In the aspect of treatment model, compared with BOT model, PPP model significantly improves the happiness of sewage treatment, the higher the level of other three factors is, the more intense the happiness will be.

\section{Conclusion}

Starting from happiness experience of sewage treatment facilities, this paper deconstructs it as villagers' happiness experience of sewage treatment facilities and tourists' happiness experience of 
sewage treatment facilities, and this paper also studies the influential factors on this happiness. The following conclusions are drawn:

(1) In the matter of relationships among influential factors of happiness, there is a strong correlation between daily management of treatment facilities and village committees' cognition and service and between that and operating and investment modes of treatment facilities; while the correlations between operating and investment modes and village committees' cognition and service, and between objection condition and other factors are relatively weak.

(2) For overall happiness, the influences of those four factors are all significant, in which the influence of investment and operating models of treatment facilities, and objective condition is highly significant, and the influence of the investment and operating models is that the happiness improvement by applying PPP model is far better than BOT model.

(3) Factors influencing villagers' happiness consist of three factors, investment and operating models of treatment facilities, daily management of treatment facilities, and objective condition of villages and towns, but the influence of village committees' cognition and service is not significant, the reason for which may be that village committees' cognition and understanding of sewage treatment facilities cannot be transformed into the motivation to provide better service for villagers in an effective way.

(4) Factors influencing tourists' happiness include investment and operating models of treatment facilities, village committees' cognition and service, and objective condition of villages and towns, but the influence of daily management of treatment facilities is not significant, the reason for which may be that tourists usually stay for 1-2 days in villages and towns, and the water environment change in towns and villages brought by facilities' daily management level can only be observed from a long-term effect.

In a nutshell, with improvement of user happiness of sewage treatment facilities in villages and towns as the purpose, first of all, sewage treatment investment and operating models transforming from BOT to PPP should be actively promoted, and user happiness experience ought to improved from the aspect of operating model. Second, the function of village committees ought to be strengthened, for example, information disclosure level in villages can be further elevated, to achieve the objective of increasing villagers' understanding of the change of sewage treatment level, and improving supervision of management and operating conditions of sewage treatment facilities.

\section{References}

[1] Li Yan, Zhao Jun. Study overview of happiness [J]. Journal of Shenyang Normal University (Social Science Edition), 2004(02):22-26.

[2] Diener E, Emmons R A, Larsen R J, Griffin S. The satisfaction with life scale. Journal of Personality Assessment, 1985, 49:7l-75l.

[3] Li Shunyi. Green development and residents' happiness-based on empirical analysis of data from Chinese General Social Survey [J]. Finance and Trade Research, 2017, 28(01):1-12.

[4] Wang Bing, Yang Bao. Village public expenditure scale, structure and peasants' happiness [J]. China Public Administration, 2018(02):53-57.

[5] Guo Lei, Xiao Youzhi. Whether governmental regulation reform promotes social public welfare-empirical evidence from dynamic panel data of water affairs industry in China's interprovincial city [J]. Management World, 2016(08):73-85.

[6] Guo Lei, Xiao Youzhi. Study of influence of governmental regulation reform on residents' happiness - empirical evidence based on data of water affairs regulation reform [J]. Social Sciences in Nanjing, 2016(08):74-81.

[7] Song Ningning, Chen Chuanyun, Shi Zuozhi, Yan Zhenzhong. Discussion of management mode of special permission of sewage treatment in villages and towns [J]. City and Town Water Supply, 2016(01):71-73. 